\title{
Uncertainty propagation on damage evolution of a concrete structure subjected to coupled leaching and creep
}

\author{
Thomas de Larrard* - Farid Benboudjema* \\ Jean-Baptiste Colliat* - Jean-Michel Torrenti** \\ Frédéric Deleruyelle ${ }^{* * * *}$ \\ * LMT-ENS Cachan, CNRS/UPMC/PRES UniverSud \\ 61 avenue du Président Wilson 94230 Cachan, France \\ \{delarrard, farid.benboudjema, colliat\}@lmt.ens-cachan.fr \\ ** Université Paris-Est, LCPC \\ 58 boulevard Lefebvre 75732 Paris Cedex 15, France \\ jean-michel.torrenti@lcpc.fr \\ *** IRSN, DSU/SSIAD/BERIS \\ BP 17 - 92262 Fontenay-aux-Roses - Cedex, France \\ frederic.deleruyelle@irsn.fr
}

\begin{abstract}
We introduce a model for calcium leaching and creep strain evolution. Both phenomena are coupled for the estimation of the damage time evolution. Simulations are achieved so as to quantify the influence of the input parameters variability on the structure lifespan. The most influent parameters are identified and threshold values for lifespan classification are enlighted. RÉSUMÉ. Cette étude propose une modélisation de la lixiviation du béton et des déformations de fluage. Les deux phénomènes sont couplés afin de prédire l'évolution de l'endommagement. Des simulations sont menées afin de quantifier l'influence de la variabilité des paramètres d'entrée du modèle sur la distribution des durées de vie de la structure. Des valeurs seuils (pour la classification des durées de vie) pour les paramètres les plus influents sont mises à jour. KEYWORDS: leaching, creep, damage, variability, distribution, Pearson correlation coefficient, decision tree

MOTS-CLÉS : lixiviation, fluage, endommagement, variabilité, distribution, coefficient de corrélation de Pearson, arbre de décision
\end{abstract}

EJECE - 14/2010. Damage mechanics for concrete materials, pages 891 à 921 


\section{Introduction}

Deep nuclear waste disposal facilities need to be studied over periods of one or more order of magnitude greater than those of classical civil engineering. This leads to consider some degradation phenomena that are most of the time not taken into account because of their slow kinetics. This is the case with calcium leaching for concrete structures exposed to water from the host rock in a deep underground storage. Calcium leaching leads to important changes in the concrete microstructure, and especially a large increase of porosity (Adenot, 1992; Gérard, 1996). Therefore, the mechanical properties of the leached material are much below those of the sound one (Carde et al., 1996; Nguyen et al., 2007a).

Moreover, civil engineering constructions are naturally subjected to variability, from many origins: their dimensions, their construction processes, their exposure to several loadings... Among these variables, which influence the behaviour of the structure and, thus, its lifespan, some of them introduce a variability on the material characteristics, evolving with time and not necessary homogeneous in the whole structure, whereas some others create a variability on the loading itself, which the structure is subjected to.

To investigate the influence of the material properties variability on the long-term behaviour of concrete structures, a very simple structure such as a column only made of concrete (without any reinforcement) is considered. This column, whose diameter is $40 \mathrm{~cm}$, is submitted to a constant mechanical load, and thus subjected to creep, and exposed to a calcium leaching attack by pure water at the same time. The coupling between creep and leaching is modelled as proposed by Torrenti et al. (2008). The column is submitted to pure compression, and the load is equivalent to $30 \%$ of the characteristic compressive strength $f_{c}$ of the material. We assume that only the sound material can sustain loads so that the stresses in the degraded area are neglected. This means that, as long as the degradation depth increases, the surface carrying the mechanical load decreases as well.

The main purpose of this paper is to investigate the uncertainty propagation from the input parameters of a very simple model to an output of interest, being the lifespan of a concrete column. Therefore, very strong assumptions are considered (uniaxial stress state, unidirectional degradation front in leaching, coupling with creep only, etc.) and the conclusions drawn from this study cannot be extended to more complex structures.

In the first section of this paper, we present the model for calcium leaching. Then the model for the damage evolution in time, taking into account the chemical degradation and the creep strain evolution, is discussed. In the third section, the input parameters variability is investigated. In the last section, the simulations results, in terms of lifespan distribution, are discussed and we determine which parameters of the model are the most influent on the lifespan variability. We also propose threshold values for the most influential parameters so as to establish a classification of the considered structures, according to their lifespan. 


\section{Calcium leaching modelling}

The phenomenon of leaching consists in the dissolution of solid calcium in cement hydrates when concrete is exposed to any aggressive solution (most of the time pure water or at least water with low calcium concentration). Indeed, concrete porous solution is very basic ( $\mathrm{pH}$ around 13) and several ionic species are highly concentrated (Torrenti et al., 1999). Therefore, water with low mineral concentration is an aggressive environment for concrete. Concentration gradients between external environment and porous solution induce diffusion of the main ionic species (alkalis, calcium, hydroxides) from the porous solution to the external environment. Consequently, the initial chemical equilibrium between the porous solution and the solid phases of the material is modified. A new local equilibrium is then reached with the dissolution of solid phases.

Calcium leaching is completely controlled by the thermodynamic equilibrium between cement hydrates and the porous solution. Thus, it might be described by considering the hydrates solubility evolution with $\mathrm{pH}$ (Berner, 1988; Thomas et al., 1998; Harris et al., 2002; Chen et al., 2004). Therefore the complete thermodynamic evolution of the material depends on a $\mathrm{CaO}-\mathrm{SiO}_{2}-\mathrm{H}_{2} \mathrm{O}$ system. Nevertheless a simplified model has been proposed only considering the different calcium phases of the hydrates (Buil et al., 1992a; Tognazzi, 1998). This approach is used in this study.

\subsection{Calcium mass balance equation}

A review of the literature (Adenot, 1992; Tognazzi, 1998) shows that the different calcium-based minerals in cement paste dissolve successively, beginning with portlandite, followed by mono-sulfoaluminate and ettringite and a progressive dissolution of C-S-H (Moranville et al., 2004; Guillon, 2004). The degraded depth in the leached cement paste may be defined as the zone where portlandite is dissolved (the dissolution front is very sharp). Porosity increases significantly within this zone due to this dissolution phenomenon. Moreover, the dissolution kinetic of solid calcium phases is much faster than the diffusion process (Bajza et al., 1986; Gérard, 1996; Schrefler, 2002).

Considering that the dissolution is instantaneous (local equilibrium) and that only calcium species are to be taken into account, the leaching of a cement paste can be described by the mass balance Equation of calcium [1], as it was proposed by Buil et $a l$. (1992b), where $S_{C a}$ is the solid calcium concentration, $C_{C a}$ is the liquid calcium concentration, $D$ is the calcium effective diffusivity in porous material and $\phi$ is the porosity. One can recognise the two main phenomena involved in the leaching process: on the one hand, the solid and liquid phases of calcium in the cement paste and in the porous solution are in chemical equilibrium; on the other hand, the ionic calcium species diffuse through the material porosity. 


$$
\frac{\partial\left(C_{C a} \phi\right)}{\partial t}=-\operatorname{div}\left(-D(\phi) \operatorname{grad}\left(C_{C a}\right)\right)-\frac{\partial S_{C a}}{\partial t}
$$

The non-linearity of the former equation is mainly due to the diffusivity which depends on the porosity, itself depending on the solid calcium concentration, and on the non-linearity between $S_{C a}$ and $C_{C a}$. The numerical solution of this equation has already been attempted through the Finite Difference method (Moskowicz et al., 1996) and the Finite Element method (Celia et al., 1990), but the Finite Volume method (Eymard et al., 1998; Mainguy et al., 2000) seems to be more suitable for our concern. Indeed it is well adapted to diffusion problems because its equations remain conservative. This is why a Finite Volume scheme has been chosen to pursue this study.

\subsection{Calcium diffusivity evolution}

Considering the chemical laws of local equilibrium between the concentrations of liquid and solid calcium, every quantity appearing in [1] can be derived from the concentration of solid calcium, which reduces the problem to a single variable $S_{C a}$. Figure 1 illustrates the empirical laws used to derive the values of the liquid calcium concentration (Figure 1a, after Berner (1990); cf. also (Gérard et al., 1998; Ulm et al., 1999; Gérard et al., 2002) about the use of such empirical laws for the chemical equilibrium of calcium) and of the porosity (Figure 1b, after Revertégat et al. (1992)) from the solid calcium concentration.

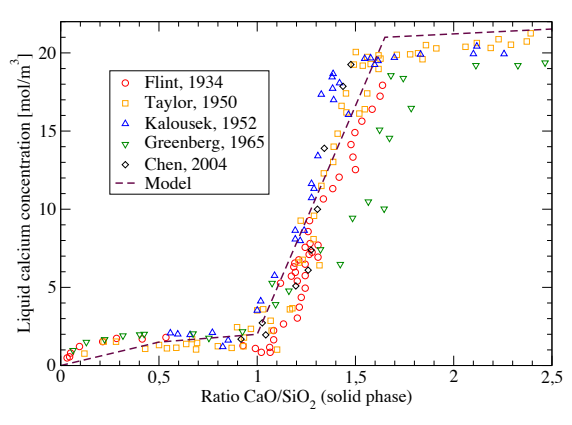

(a) Liquid calcium concentration, after Berner (1990)

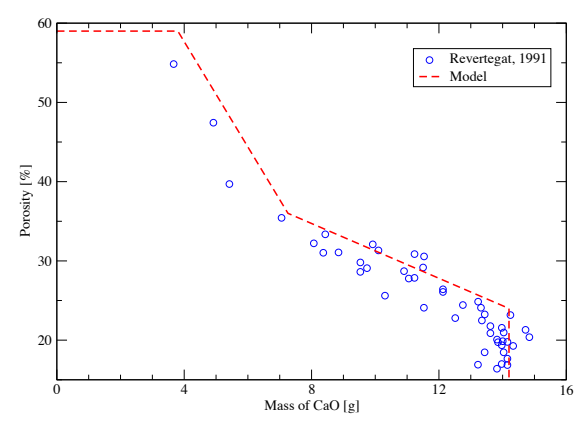

(b) Porosity, after Revertégat et al. (1992)

Figure 1. Solid calcium concentration as reference variable

As mentioned before, the non-linearity of the leaching equations is also due to the dependancy of the calcium diffusivity through the cement paste on the porosity. The law used to model this dependancy [2] was proposed by Mainguy et al. (2000) and 
fits accurately experimental data (Adenot, 1992; Richet et al., 1997) as it appears on Figure 2. The values for the diffusion parameters proposed by Mainguy et al. (2000) are $D_{0}=2.355 \cdot 10^{-13} \mathrm{~m}^{2} . \mathrm{s}^{-1}$ and $k=9.95$. It is worth noticing that these results have been validated on sound materials, their porosity changing with respect to the water/cement ratio. It is a fundamental hypothesis that the diffusivity follows the same evolution when the porosity increases through the leaching process. This evolution was validated by Kamali-Bernard et al. (2009) through multiscale simulations.

$$
D(\phi)=D_{0} e^{k \phi}
$$

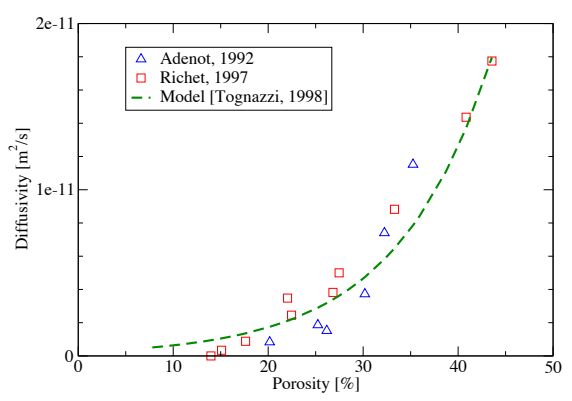

Figure 2. Empirical law to model calcium effective diffusivity in cement paste with respect to porosity

\subsection{From cement paste to concrete: introduction of tortuosity}

Considering concrete rather than cement paste requires a few more assessments, the first one being that the leaching phenomenon concerns only the calcium solid phases of the cement paste (meaning that the aggregates do not interfere with the dissolution process). Another hypothesis is that diffusion occurs only through the cement paste porosity. The last hypothesis stands for the opposite effects of aggregates on the diffusion process, because on the one hand aggregates are areas where no diffusion occurs, but on the other hand they introduce an Interfacial Transition Zone where the diffusivity can increase due to a larger porosity of the ITZ in comparison with bulk cement paste (Bourdette, 1994; Bentz et al., 1995; Ollivier et al., 1995). It is to be noticed that these effects of aggregates over the diffusion kinetic could be selfcompensated for small aggregates (sand): no significant difference in the kinetic of the diffusion process was observed between a cement paste and a mortar made up with the same water/cement ratio (Tognazzi, 1998; Nguyen et al., 2007a). Nevertheless, this observation is no longer valid when concrete is considered, with large inclusions: the distance that the species in the porous solution have to cover to reach a given penetration depth in the material is increased because of the tortuosity introduced by large aggregates. 
This leads to the introduction of a tortuosity parameter $\tau$ standing for those possible opposite effects of aggregates. This approach was successfully used by Nguyen et al. (2006) and appears in [3] in order to express the diffusivity of calcium species through concrete depending on the cement paste porosity.

$$
\widetilde{D}(\phi)=\tau D_{0} e^{k \phi}
$$

The implementation and validation of this numerical model are presented in Larrard de et al. (2010); this latter study also enhances that the most influential parameters on the leaching phenomenon kinetics are the porosity and the tortuosity.

To evaluate the lifespan of the concrete structure under a mechanical load and a calcium leaching attack, it is assumed that only the sound part of concrete would carry the load and that no stress could be transmitted through the degraded area. Thus, the effective area of concrete would reduce as leaching progresses, as proposed by Torrenti et al. (2008).

\section{Damage evolution coupled with leaching and creep}

\subsection{Creep modelling}

It is still a difficult task to assess the creep behaviour of concrete, since the associated mechanisms are not well known (Jennings et al., 1992). When compressive stresses level becomes important, it is noticeable that the relation between creep strain and stress becomes non linear (Roll, 1964; Li, 1994; Mazzotti et al., 2003). Many modelling approaches have been proposed, among which the following ones seem the most accurate.

- From damage theory, Li (1994) proposed that the temporal variable can be explicitly introduced in the mechanical damage evolution law (in terms of damage rate). One of the shortcomings of this approach is that it is dissociated with linear viscoelastic creep strain.

- According to Bazant et al. (1997b), this non linearity is only apparent: the non linear creep does not exist from their point of view. Non linearity is the result of micro-cracks growing with time. They proposed a time-dependent generalisation of the R-curve model (adaptation of LEFM which considers the process zone as a point), in which the crack growth rate depends on the ratio of the stress intensity factor to the R-curve.

- The non linear character can be supposed to be linked to the stress redistribution because of creep, and to the non homogeneous damage distribution (Ozbolt $e t$ $a l ., 2001)$. Indeed, cracking in a concrete specimen is heterogeneous: it occurs in a localised area. Thus, the redistribution takes place between the most damaged areas and the less damaged ones. This hypothesis requires that modelling takes into account the 
material initial defaults, which can corrupt the stress and strain distribution (initially homogeneous).

- The linear visco-elastic model can be extended by multiplying the creep compliance by a non-linear function of the stress-state (Bazant et al., 1989). This function is equal to one for low stress levels.

- Coupling between creep and cracking can be modelled by combining a viscoelastic and a viscoplastic model as proposed by Berthollet et al. (2002). This model is built on Duvault-Lion approach in which a generalised Maxwell model is integrated. It reproduces with a satisfactory accordance linear visco-elastic creep, creep failure and rate effect on strength.

- Mazzotti et al. (2003) proposed to model non-linear creep strain by introducing a stress rate reduction factor as a function of the damage variable in the solidification model of Bazant et al. (1989). Moreover, an effective strain is then defined for creep damage, replacing the equivalent strain (as defined by Mazars (1986)) in damage evaluation for instantaneous loading case. The effective strain is defined as the sum of instantaneous damaged elastic strain with a fraction of creep strain. Omar et al. (2003) also used a similar approach.

Among these approaches, our model is based on the one proposed by Mazzotti et al. (2003), since the use of damage allows a simple and natural coupling with creep and leaching through the use of the effective stress concept. It is coupled with the model proposed for creep strain evolution by Bazant et al. (1997a), based on the microprestress theory. This model turns out to be particularly accurate when considering the very long time creep, and is in good accordance with experimental results (cf. the experimental campaign by Brooks (2005) for 30 years creep). The approach proposed by Mazzotti et al. (2003) was used by Reviron et al. (2007) and Reviron (2009) with satisfactory results to model concrete creep as well in compression and tension in comparison with experimental results.

\subsection{Long-time creep strain prediction with microprestress theory}

Bazant et al. (1997a) proposed a creep modelling based on the microprestress solidification theory. For a unidirectional problem, the mechanical behaviour can be schematically represented as illustrated on Figure 3.

\subsubsection{Microprestress relaxation mechanism}

The microprestress solidification theory leads to introduce a flow element whose viscosity depends on the microprestress so as to represent the microprestress relaxation mechanism. Therefore, this model is able to reproduce accurately ageing, even after hydration is completed. Microprestress is a stress level induced in the material by capillary pressure, evolving with time during the hydration process and with pore humidity. The strain evolution $\widehat{\varepsilon}$ for this flow element is given by [4], where $\widehat{\sigma}$ is 
the effective stress imposed to the material (cf. Subsection 3.3.2), $\eta$ is the element viscosity and $S$ is the microprestress.

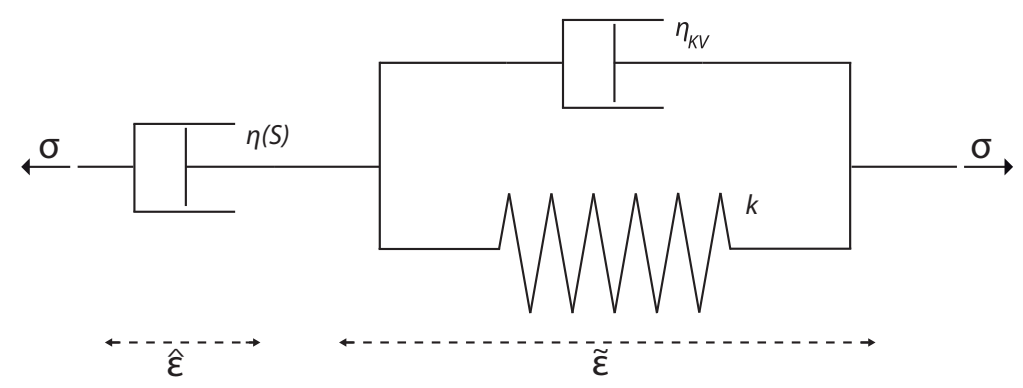

Figure 3. Creep mechanical model corresponding to the microprestress-solidification theory: $\widehat{\varepsilon}$ stands for the strain of the flow element with viscosity depending on microprestress (microprestress relaxation mechanism); $\widetilde{\varepsilon}$ stands for the strain of a KelvinVoigt chain

$$
\frac{d \widehat{\varepsilon}}{d t}=\frac{\widehat{\sigma}}{\eta(S)}
$$

The difficult part with this approach is to determine the viscosity evolution with microprestress as well as microprestress evolution with time. In the case of a saturated (meaning that there are neither drying nor wetting phenomena during the degradation and creep processes) and already aged structure (i.e. no hydration process is ongoing during the load application), microprestress and viscosity evolutions are quite simple (Bazant et al., 1997a) and leads to Equation [5], where $\alpha$ is a creep parameter that remains constant and depends only on the material. When considering a totally implicit numerical integration scheme where stress is regarded as constant on a timestep, Equation [5] becomes [6], where $t_{n}$ is the former timestep and $t_{n+1}$ the current one, so that $\widehat{\sigma}_{n+1}$ is the effective stress (constant between $t_{n}$ and $t_{n+1}$ ), $\widehat{\varepsilon}_{n}$ is the known strain at $t_{n}$ and $\widehat{\varepsilon}_{n+1}$ is the unknown strain at $t_{n+1}$.

$$
\begin{aligned}
& \frac{d \widehat{\varepsilon}}{d t}=\widehat{\sigma}_{n+1} \frac{\alpha}{t} \\
& \widehat{\varepsilon}_{n+1}=\widehat{\varepsilon}_{n}+\widehat{\sigma}_{n+1} \alpha \ln \left(\frac{t_{n+1}}{t_{n}}\right)
\end{aligned}
$$




\subsubsection{Creep recovery}

The main disadvantage of the flow element is that it does not allow to represent the creep recovery: when the load is removed, no recovery can be modelled by the flow element ( $\widehat{\sigma}=0$ in Equation [4]). Therefore a Kelvin-Voigt chain is introduced (cf. Figure 3). The Kelvin-Voigt element is composed by a viscous damper (viscosity $\eta_{K V}$ ) and an elastic spring (stiffness $k$ ) connected in parallel. Illston (1965) shows that the creep recovery lasts for approximatively one week and this is why we consider a value of 7 days for the characteristic time $\tau_{K V}=\eta_{K V} / k$ of the Kelvin-Voigt chain. The strain evolution for the Kelvin-Voigt element is given by Equation [7], where $\widetilde{\varepsilon}$ is the creep strain for the element under a stress $\widehat{\sigma}$. If one considers the same totally implicit numerical integration scheme as formerly, one obtains Equation [8], where $\Delta t$ is the timestep.

$$
\begin{aligned}
& \frac{\widehat{\sigma}}{k}=\widetilde{\varepsilon}+\tau_{K V} \frac{d \widetilde{\varepsilon}}{d t} \\
& \widetilde{\varepsilon}_{n+1}=\widetilde{\varepsilon}_{n} e^{-\Delta t / \tau_{K V}}+\frac{\widehat{\sigma}_{n+1}}{k}\left(1-e^{-\Delta t / \tau_{K V}}\right)
\end{aligned}
$$

Equations [6] and [8] allow, within a totally implicit integration numerical scheme, to determine the total creep strain $\left(\widehat{\varepsilon}_{n+1}+\widetilde{\varepsilon}_{n+1}\right)$ from the creep strains values at the former timestep and the stress value during the timestep $\sigma_{n+1}$. This value evolves with time as damage increases in the material. These equations are extended in $3 \mathrm{D}$, by the use of a creep Poisson ratio, which is taken equal to the elastic one (cf. Subsection 3.3.3).

\subsection{Coupled mechanical and chemical damage}

The coupling between mechanical behaviour (especially the damage evolution) and chemical degradation of concrete has been much studied (Carde et al., 1996; Carde et al., 1997; Saetta et al., 1998; Torrenti et al., 2008; Bangert et al., 2001; Nguyen et al., 2007b). Let us especially mention the model proposed by Gérard (1996) and Gérard et al. (1998) who proposed a simplified modelling for chemical alteration and a coupling with the damage evolution proposed by Mazars (1986). The coupling appeared through the evolution of the coefficient of diffusion depending on the damage variable. The model proposed by Ulm et al. (1999) is based on the theory of porous media and enhances to couple the hydrates dissolution with the evolution of porosity and strain. The model of Kuhl et al. (2003a) and Kuhl et al. (2003b) proposes to consider three parts for porosity (initial porosity, porosity due to chemical degradation and porosity due to mechanical damage). It is very accurate to model that the chemical and mechanical degradations are non-reversible. Let us at last mention the 
work by Lacarrière et al. (2006), who showed that is possible to model creep also in the degraded area.

\subsubsection{Chemical damage}

A chemical damage variable $D^{\chi}$ is associated to the leaching degradation process of concrete (cf. Section 2) and is defined as the ratio of the degraded area over the whole material section. For the considered cylinder, whose radius is $R$ (taken equal to $20 \mathrm{~cm}$ in our concern), if the degradation depth at time $t_{n+1}$ is denoted $e_{n+1}$, the chemical damage variable at $t_{n+1}$ is denoted $D_{n+1}^{\chi}$ and appears in Equation [9]. This definition of the chemical damage variable relies on the hypothesis of an unidirectional degradation front. Therefore, the conclusions drawn from this study cannot be directly extended to more complex structures, for which the degradation has to modelled in 3 dimensions.

$$
D_{n+1}^{\chi}=\frac{e_{n+1}}{R}\left(2-\frac{e_{n+1}}{R}\right)
$$

Studies led on degraded materials (Carde et al., 1996; Gérard, 1996) have quantified the loss of residual mechanical properties for leached concrete. This decrease mainly depends on the mineral admixtures in the concrete mix design and on the degraded area which is considered (dissolution of portlandite only does not lead to very significant decrease of the compressive strength, whereas dissolution of C-S-H does). For a sake of simplicity, and because of a lack of experimental results on the mechanical of the degraded considered material, it will be considered in this study that the leached area does not sustain any load. Indeed, considering more important residual mechanical properties for the degraded areas would lead to introduce more input parameters in our model, and, therefore, more variability. Such strong hypothesis about the mechanical behaviour of the degraded area has already been used by Torrenti $e t$ $a l$. (2008) and leads to an under-estimation of the lifespan of the considered structure (which is in acceptable accordance with a view of preserving the safety of concrete structures).

Figure 4 shows how the chemically effective stress $\widetilde{\sigma}$ is defined from the apparent stress $\sigma$ applied on the whole material section (included the degraded area): we assume that the stress that is actually applied on the chemically sound area is increased according to the same ratio that the section is reduced. Therefore, the expression of the chemically effective stress $\widetilde{\sigma}_{n+1}$ at time $t_{n+1}$ is given in Equation [10].

$$
\widetilde{\sigma}_{n+1}=\frac{\sigma}{1-D_{n+1}^{\chi}}
$$

Due to this stress increase with the chemical degradation process, microcracks appear in the material and lead to the introduction of a mechanical damage $D^{c}$. 


\subsubsection{Mechanical damage evolution}

The scalar mechanical damage variable $D^{c}$ is associated to the mechanical degradation process of concrete induced by the development of microcracks. It is defined as the ratio between the microcracks area to the whole material area. This mechanism is illustrated on Figure 4: the effective stress $\widehat{\sigma}$ applied on the un-cracked and chemically sound material is thus deduced from the apparent stress $\sigma$, and the chemical and mechanical damage variables $D^{\chi}$ and $D^{c}$, as it appears in Equation [11] where $\widehat{\sigma}_{n+1}$ is the effective stress at time $t_{n+1}$.

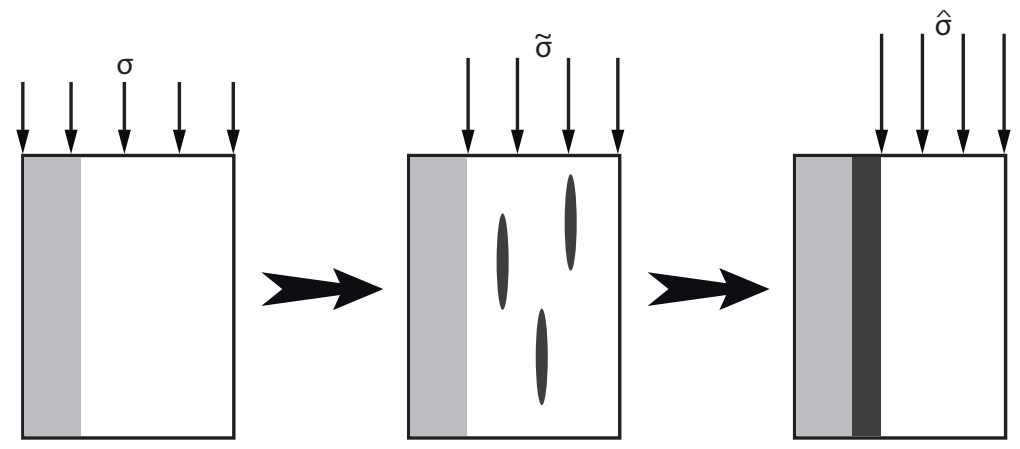

Figure 4. Definition of effective stress on damaged material: no stress is sustained by the chemically damaged section (light grey), so the real stress $\sigma$ becomes $\widetilde{\sigma}$ on the sound material (white). Due to mechanical damage, cracks in the sound material (deep grey) reduces the material section to sustain the load, and thus introduce an effective stress $\widehat{\sigma}$ on the uncracked sound material

$$
\widehat{\sigma}_{n+1}=\widehat{\sigma}\left(t_{n+1}\right)=\frac{\sigma}{\left(1-D_{n+1}^{\chi}\right)\left(1-D_{n+1}^{c}\right)}
$$

The mechanical damage variable represents the effect of progressive microcracking, due to external mechanical loads, in term of degradation of the current Young modulus. The mechanical damage evolution is modelled as proposed by Mazars (1984) and Mazars (1986). It is deduced from the Mazars equivalent tensile strain $\varepsilon^{e q}$ defined in [12], where $\langle\varepsilon\rangle_{+}$is the positive part of the strain tensor. The evolution law for the mechanical damage variable is given in Equation [13], where $\varepsilon_{D}$ is the damage tensile strain threshold, $A$ and $B$ are constant material parameters which control the hardening/softening branch in the stress-strain curve.

$$
\varepsilon^{e q}=\sqrt{\langle\varepsilon\rangle_{+}:\langle\varepsilon\rangle_{+}}
$$




$$
D^{c}=1-\frac{\varepsilon_{D}(1-A)}{\varepsilon^{e q}}-\frac{A}{\exp \left(B\left(\varepsilon^{e q}-\varepsilon_{D}\right)\right)} \quad \text { if } \quad \varepsilon^{e q} \geq \varepsilon_{D}
$$

\subsubsection{Coupling between creep and damage}

The coupling between creep and damage is taken into account twice. On the one hand, creep strains are considered to be driven by effective stresses (only the uncracked material creeps as shown in Benboudjema et al. (2005a) and Benboudjema et al. (2008)). It slightly increases creep strains after damage occurs in compression, but it is not sufficient for correctly retrieving non-linear creep. On the other hand, the calculation of the equivalent strain [14] includes a part of creep strains through a material parameter $\beta$, which can be identified from non linear basic creep data (Mazzotti et al., 2003). Therefore, damage is also affected by basic creep strain. This allows to accurately retrieve non-linear basic creep evolution for high stress levels. In Equation [14], $\mathscr{E}^{e}$ is the elastic strain tensor, $\widehat{\mathbb{E}}$ is the flow element strain tensor and $\widetilde{\mathscr{E}}$ is the Kelvin-Voigt element strain tensor.

$$
\varepsilon^{e q}=\sqrt{\left\langle\mathscr{E}^{e}+\beta(\widehat{\mathscr{E}}+\widetilde{\mathscr{E}})\right\rangle_{+}:\left\langle\mathscr{E}^{e}+\beta(\widehat{\mathbb{E}}+\widetilde{\mathbb{E}})\right\rangle_{+}}=\sqrt{\langle\overline{\mathscr{E}}\rangle_{+}:\langle\overline{\mathscr{E}}\rangle_{+}}
$$

In this study, the considered structure is a column in pure compression, so that the tensile eigenstrains are proportional to the compressive eigenstrain through the apparent Poisson ratio $\nu$, as it appears in Equations [15], [16], [17] and [18] showing respectively the equivalent stress tensor, the resulting elastic strain tensor, the equivalent strain tensor $\bar{\Phi}$ (including creep strains, with the coupling coefficient for the damage evolution) and the total strain tensor $\varepsilon$.

$$
\begin{aligned}
& \widehat{\sigma}=\left[\begin{array}{lll}
\widehat{\sigma} & 0 & 0 \\
0 & 0 & 0 \\
0 & 0 & 0
\end{array}\right] \\
& \mathcal{E}^{e}=\left[\begin{array}{ccc}
\widehat{\sigma} / E & 0 & 0 \\
0 & -\nu \widehat{\sigma} / E & 0 \\
0 & 0 & -\nu \widehat{\sigma} / E
\end{array}\right]=\left[\begin{array}{ccc}
\varepsilon^{e} & 0 & 0 \\
0 & -\nu \varepsilon^{e} & 0 \\
0 & 0 & -\nu \varepsilon^{e}
\end{array}\right] \\
& \bar{\varepsilon}=\left[\begin{array}{ccc}
\varepsilon^{e}+\beta(\widehat{\varepsilon}+\widetilde{\varepsilon}) & 0 \\
0 & -\nu\left(\varepsilon^{e}+\beta(\widehat{\varepsilon}+\widetilde{\varepsilon})\right) & 0 \\
0 & 0 & -\nu\left(\varepsilon^{e}+\beta(\widehat{\varepsilon}+\widetilde{\varepsilon})\right)
\end{array}\right]
\end{aligned}
$$




$$
\varepsilon=\left[\begin{array}{ccc}
\varepsilon^{e}+\widehat{\varepsilon}+\widetilde{\varepsilon} & 0 & 0 \\
0 & -\nu\left(\varepsilon^{e}+\widehat{\varepsilon}+\widetilde{\varepsilon}\right) & 0 \\
0 & 0 & -\nu\left(\varepsilon^{e}+\widehat{\varepsilon}+\widetilde{\varepsilon}\right)
\end{array}\right]
$$

Under the hypothesises of the previously mentioned totally implicit integration numerical scheme, Equation [19] gives the expression of the equivalent strain $\varepsilon_{n+1}^{e q}$ at $t_{n+1}$ from the Poisson ratio $\nu_{n+1}$, the elastic compressive strain $\varepsilon_{n+1}^{e}$ (cf. Equation [20]), the flow and Kelvin-Voigt creep strains $\widehat{\varepsilon}_{n+1}$ (cf. Equation [6]) and $\widetilde{\varepsilon}_{n+1}$ (cf. Equation [8]).

$$
\begin{aligned}
& \varepsilon_{n+1}^{e q}=\sqrt{2 \nu_{n+1}^{2}\left(\varepsilon_{n+1}^{e}+\beta\left(\widehat{\varepsilon}_{n+1}+\widetilde{\varepsilon}_{n+1}\right)\right)^{2}} \\
& \varepsilon_{n+1}^{e}=\frac{\widehat{\sigma}_{n+1}}{E}
\end{aligned}
$$

An extensive survey on creep Poisson ratio shows that its value (for basic creep) is slightly lower than the elastic one (Benboudjema, 2002). Moreover, it is different for sound and leached material (Heukamp et al., 2001). Such differences can be easily taken into account in the model. However, it is difficult again to estimate the variability of such parameters due to the lack of extensive data. Therefore, an identical Poisson ratio for elastic and creep strain for sound and leached parts is assumed.

The use of an isotropic damage model does not allow to retrieve dilatancy since tensile strains drive mechanical damage. Indeed, tensile strains increase faster than the compressive longitudinal strain after cracking and, thus, lead to dilatancy. This shortcoming is an important concern. The use of an elasto-plastic damage model or an anisotropic damage one (Benboudjema et al., 2005b; Jason et al., 2006) allows for retrieving dilatancy. However, it will lead to add more material parameters, which variability is difficult to estimate. Therefore, for a sake of simplicity, an evolution of apparent Poisson ratio has been considered in order to reproduce dilatancy, under the hypothesis of uniaxial stress states. This evolution is defined as a function of the longitudinal total strain [21], where $\nu_{0}$ is an initial Poisson ratio, $\widetilde{\nu}$ and $\gamma$ are material parameters determined through a best fit procedure in comparison with experimental data by Kupfer et al. (1969). This model as well as the values for $\nu_{0}, \widetilde{\nu}$ and $\gamma$ were proposed by Mazzotti et al. (2003). Some studies (Torrenti et al., 2008) used a similar approach but considered a constant Poisson ratio, which lead to different values for the coupling coefficient $\beta$.

$$
\nu_{n+1}=\nu_{0}\left(1+\widetilde{\nu}\left(\varepsilon_{n+1}^{e}+\widehat{\varepsilon}_{n+1}+\widetilde{\varepsilon}_{n+1}\right)^{\gamma}\right)
$$




\subsubsection{Algorithm for numerical simulation}

The numerical solving algorithm for this problem is a partitioned one. In any case, the chemical degradation depth is supposed to be independent from the mechanical damage, and the leaching degradation depth is given by numerical simulations deduced from the numerical model for leaching presented in Section 2, implemented in a Finite Volume computer code (see Larrard de et al. (2010) for more details). So, for each timestep, the leaching degradation depth $e_{n+1}$ and, thus, the chemical damage $D_{n+1}^{\chi}$ are already known.

1) While the equivalent strain $\varepsilon_{n+1}^{e q}$ is below the damage threshold $\varepsilon_{D}$, there is no mechanical damage and only chemical damage is considered $\left(D_{n+1}^{c}=D_{n}^{c}\right)$. Thus, the effective stress derives from Equation [11]. Then the strains and the Poisson ratio can be evaluated with Equations [6], [8], [20] and [21]. Eventually, the equivalent strain is calculated through Equation [19].

2) When the equivalent strain $\varepsilon_{n+1}^{e q}$ reaches the damage threshold $\varepsilon_{D}$, the totally implicit numerical scheme leads to a non-linear equation with $\widehat{\sigma}_{n+1}$ as unique unknown variable. This equation is obtained by introducing in Equation [11] the expression of the mechanical damage [13] coupled with [19]. Equations [6], [8], [20] are also introduced to express any other variable as a function of the effective stress $\widehat{\sigma}_{n+1}$. This non-linear equation is solved at each timestep with a Gauss-Newton algorithm with a relative tolerance of $10^{-15}$. Afterwards, other variables of the problem can easily be derived from the effective stress value.

3) The algorithm stops when total damage reaches the critical value of 1.

Figure 5 shows an example of damage evolution with time: chemical, mechanical and total damage are plotted. The values of the input parameters corresponding to this example are presented in Table 1. Figure 6 illustrates the strains evolution with time. One can observe that elastic strain follows the mechanical behaviour of the material: it is linear at the beginning and increases very rapidly when the stress level approaches to the maximal compressive strength. The Kelvin-Voigt creep strain remains rather low in comparison with the flow creep strain. The three phases of creep evolution (primary creep at the beginning, secondary creep for a long period with a constant increase rate, and finally tertiary creep which leads very rapidly to the material failure) can be observed on both figures. The first period corresponds to the time where the equivalent strain is below the damage threshold, and, therefore, total damage is equal to chemical damage (mechanical damage is 0 ).

Figure 7a shows the apparent Poisson ratio evolution with respect to time. The Poisson ratio increases with total strain, and when the mechanical damage is sufficient, meaning that there are enough cracks in the material, the apparent Poisson ratio exceeds the value of 0.5 (which corresponds to dilatancy). This is to be compared with the sample expansion plotted on Figure 7b, on which one can observe this expansion in time and consider that the sample apparent volume ends up to get more important than the initial volume whereas the sample is still loaded in compression. 


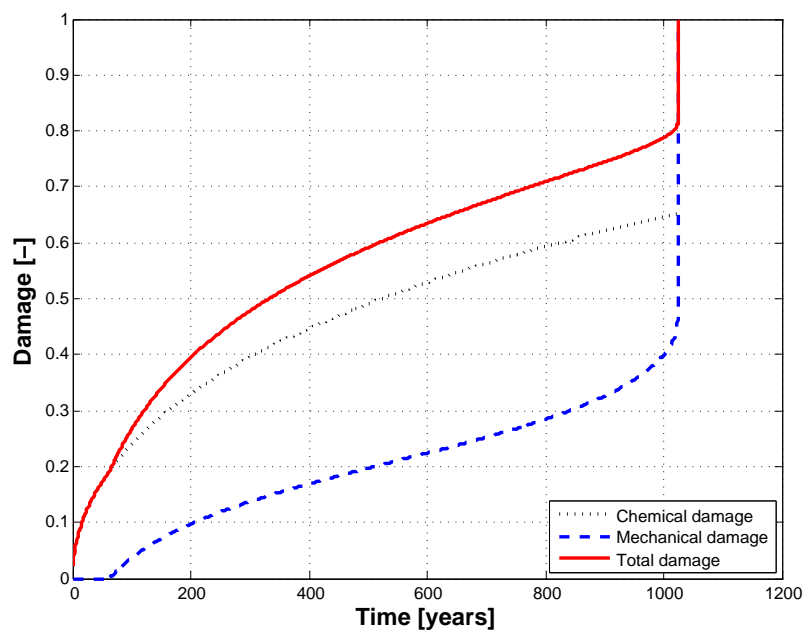

Figure 5. Total, mechanical and chemical damage time evolutions obtained in pure water

Table 1. Values of the input parameters for the simulation represented on Figures 5 , 6 and 7

\begin{tabular}{ccc}
\hline$\phi$ & {$[-]$} & 0.142 \\
$\tau$ & {$[-]$} & 0.169 \\
$E$ & {$[\mathrm{GPa}]$} & 52.3 \\
$\nu_{0}$ & {$[-]$} & 0.113 \\
$\alpha$ & {$[-]$} & $4.30 \cdot 10^{-12}$ \\
$k$ & {$[\mathrm{GPa}]$} & 157.1 \\
$\beta$ & {$[-]$} & 0.10 \\
$\varepsilon_{D}$ & {$[\mu \mathrm{m} / \mathrm{m}]$} & 138 \\
$A$ & {$[-]$} & 0.77 \\
\hline
\end{tabular}

Numerical simulations have been run with a timestep of 1 day, 70, 140, 280 and 560 days. All results are exactly the same. This means that the adopted implicit numerical scheme does not lead to timestep dependancy. Nevertheless, it has been decided to keep a timestep of 280 days, not for a reason of simulations accuracy, but to have a large amount of data concerning the damage evolution, so that the statistical investigation is more refined. 


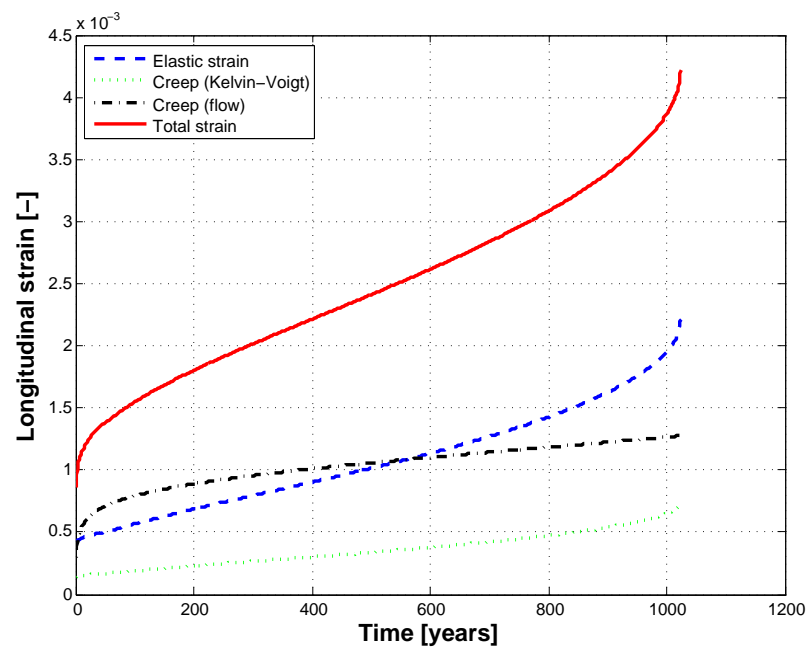

Figure 6. Elastic strain $\varepsilon^{e}$, flow creep strain $\widehat{\varepsilon}$, Kelvin-Voigt creep strain $\widetilde{\varepsilon}$ and total strain $\varepsilon^{\text {tot }}$ time evolutions

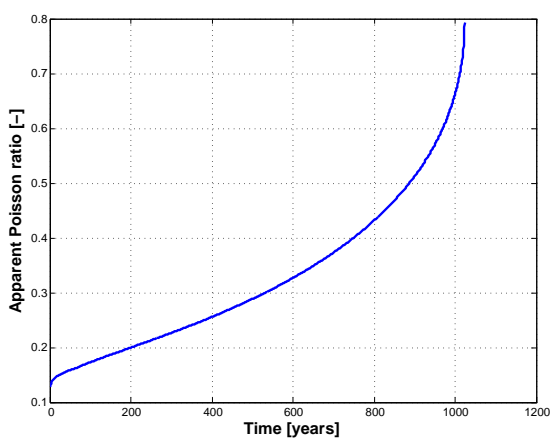

(a) Apparent Poisson ratio

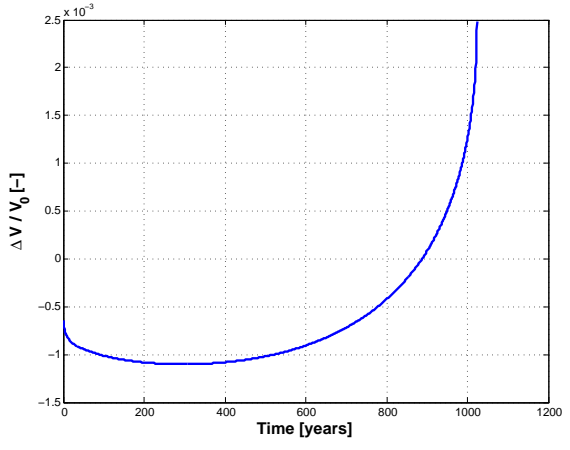

(b) Dilatancy

Figure 7. Evolution the dilatancy phenomenon with regard to time

The numerical model presented here has many input parameters, and next section discusses which of them should be regarded as a variable of the problem and which can be regarded as constant. 


\section{Input parameters variability}

Among all the input parameters of the model, those related to the leaching process can be considered separately. As presented in Section 2, two main parameters can be considered as governing the leaching process (Larrard de et al., 2010): porosity $\phi$ and coefficient of tortuosity $\tau$. Both of them are regarded as variables.

The parameters to model creep strain evolution are the flow coefficient $\alpha$ (cf. Equation [6]), the Kelvin-Voigt spring stiffness $k$ and the Kelvin-Voigt element characteristic time $\tau_{K L}$. Parameters $\alpha$ and $k$ are regarded as variables, whereas $\tau_{K L}$ is set to 7 days, which is approximatively the period for the creep strain recovery phenomenon.

The mechanical behaviour of the material is modelled thanks to the Young modulus $E$, considered as variable, and the Poisson ratio, whose evolution is given by relation [21] with parameters $\nu_{0}$ (variable), $\widetilde{\nu}$ and $\gamma$ (set constant and equal respectively to $3.37 \cdot 10^{6}$ and 2.42 , which are the experimental values proposed by Mazzotti et al. (2003)). The chemical damage evolution modelling requires the coupling coefficient $\beta$ to define the equivalent strain, and the damage strain threshold $\varepsilon_{D}$, both of them being considered as variable. At least, coefficients $A$ and $B$ appear in Equation [13]: as $A$ mainly governs the material's behaviour before having reached its compressive strength, whereas $B$ concerns rather the behaviour after the peak, it has been decided to keep $B$ constant (equal to 150) and to consider $A$ as a variable.

Finally, our model considers 9 variables as input parameters for which the variability has now to be quantified.

\subsection{Acquiring statistical data}

The data concerning the material variability used for this study are coming from the APPLET project. Only a part of this project is presented here. This project is funded by the National Research Agency (France) and involves a large experimental campaign carried out in partnership with Vinci Company. This campaign aims at acquiring statistical data on concrete properties and also the variability of these characteristics within several batches of a same formulation (Poyet et al., 2009). For this purpose, a real construction site is followed and 40 batches of concrete are characterised through several tests performed in laboratories (compressive and splitting tensile strength, static and dynamic Young modulus, electrical resistivity...). The concrete is a high-performance one with fly ash and all samples are directly provided by the construction site to the involved laboratories. The samples are protected from drying in plastic bags and then conserved at least one year in saturated lime water before testing.

Concerning the parameters of leaching, porosity is directly measured on the samples whereas the coefficient of tortuosity is identified through an inverse analysis from experimental results of an accelerated leaching test with ammonium nitrate. The experimental set up as well as the identification process are presented in Larrard de et al. 
(2010). Young modulus, compressive and tensile strength are also investigated within the APPLET project and the measures of these variables are used for this study. Indeed, the damage strain threshold $\varepsilon_{D}$ is identified as the ratio of the tensile strength over the Young modulus. The compressive strength variability will be introduced in the coefficient $A$ identification (cf. Subsection 4.2.2).

\subsection{Identification of statistical characteristics}

\subsubsection{Creep parameters}

As mentioned in Subsection 3.2, a model based on the microprestress solidification theory (Bazant et al., 1997a) has been chosen because of its ability to represent long-time creep strain evolution with a satisfactory accurancy. This model, leading to Equations [6] and [8], introduces three parameters devoted to the creep modelling: the flow coefficient $\alpha$, the Kelvin-Voigt spring stiffness $k$ and the Kelvin-Voigt element characteristic time $\tau_{K V}$. This last parameter is set equal to 7 days, but $\alpha$ and $k$ still have to be identified.

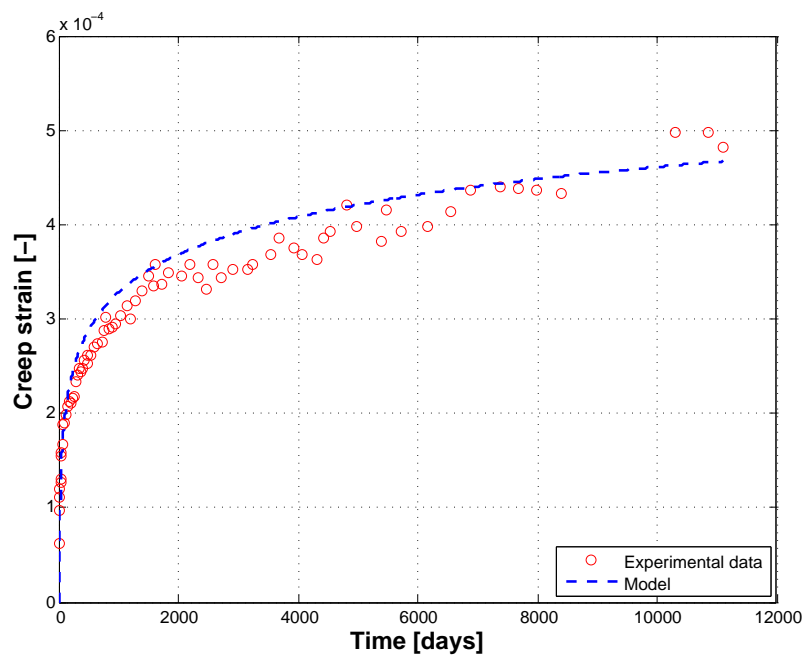

Figure 8. Long time creep strains evolution: comparison between Brooks corrected experimental results and model prediction

As the considered phenomena (leaching and creep) are studied over a very long period, it seems important to identify the creep parameters with regard to long-time experimentation. Therefore, the experimental results for long-time strain creep by Brooks (2005) have been considered: creep strain evolution have been measured over 30 years. It is to be noticed that, among all materials tested by Brooks (2005), it has been decided to consider the material whose mix design and mechanical characteris- 
tics were the closest to the ones of the APPLET concrete. The external conditions are also in good accordance with the hypothesis of our simulations: the concrete samples were subjected neither to wetting nor to drying. Anyway, the Young modulus of Brooks concrete is around $30 \mathrm{GPa}$, whereas the APPLET concrete has a $45 \mathrm{GPa}$ Young modulus. It is commonly accepted that creep parameters evolves with the same ratio that Young modulus (ACI Committee 209, 2008). Therefore, we have corrected the creep strains measured by Brooks (2005) with a 1.5 ratio. Figure 8 shows the accordance between these corrected experimental data and the considered creep model with the identified (least squares approximation, with a weighting to improve the importance of long-time measures) parameters: $k=137.7 \mathrm{GPa}$ and $\alpha=5.25 \cdot 10^{-12}$.

\subsubsection{Damage parameters}

The damage evolution law [13] was used to model the mechanical behaviour of compressed concrete. Young modulus was considered constant to its mean value, and coefficient $B$ was set to 150 . The bounds of coefficient $A$ have been identified so that the compressive strength extreme values (measured within the APPLET project experimental campaign) were reached. Therefore, coefficient $A$ ranges in the interval: $0.85 \leq A \leq 1.05$. Figure 9 shows the stress-strain curves obtained for the maximal and minimal values of A (corresponding to the observed bounds for the compressive strength).

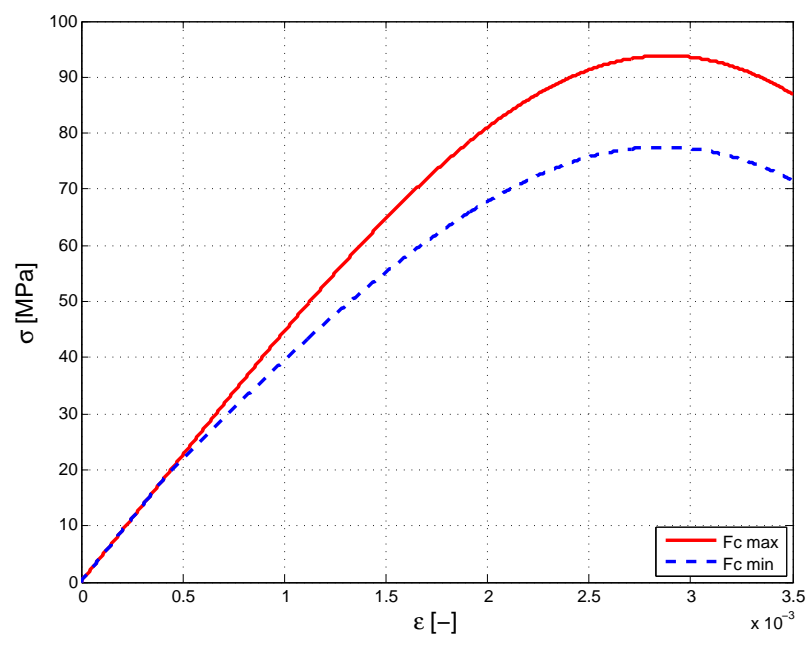

Figure 9. Mechanical behaviour of concrete

\subsubsection{Variable distributions}

To investigate the influence of the material variability on the lifespan of the structure, and to determine which parameters are the most influential on the damage evolution with time, 1000 concrete structures were simulated with the formerly presented 
algorithm (cf. Subsection 3.3.4). The 1000 corresponding sets of input parameters were randomly generated according to the Latin Hypercube Sampling principle (McKay et al., 1979), optimised thanks to a simulated annealing algorithm (Kirkpatric et al., 1983).

Each of the 9 variables is distributed according to a Beta $(2,2)$ distribution. This kind of distribution has been chosen because of its rather good accordance with the experimental data from the APPLET project, and also because the generated variables remain in a given interval. Figure 10 illustrates the Young modulus distribution for the 1000 realisations.

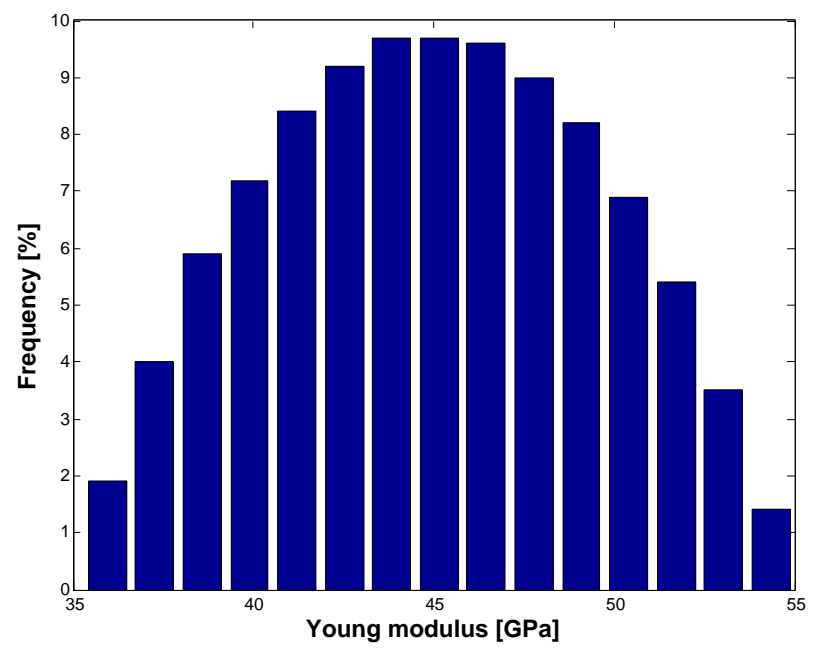

Figure 10. Young modulus distribution for the considered 1000 realisations (according to a Beta-distribution)

The expected value and standard deviation for each variable parameter of the model is presented in Table 2. For parameters $\phi, \tau, E$ and $\varepsilon_{D}$, probabilistic data derives directly from the APPLET experimental campaign results. The expected values for $\alpha$ and $k$ have been identified (cf. Subsection 4.2.1), and it has been chosen to consider a coefficient of variation equal to the Young modulus one. The expected values for $\beta$ and $\nu_{0}$ are from the works by Mazzotti et al. (2003). The standard deviation for these parameters are also a synthesis of what can be found in the litterature (Reviron et al., 2007; Berveiller et al., 2007; Torrenti et al., 2008; Reviron, 2009). The bounding values for coefficient $A$ were identified (cf. Subsection 4.2.2) to match with the bounding values of compressive strength observed within the APPLET experimental campaign. All the variables are considered to be independent. It should be noticed that this is in accordance with experimental results. Indeed, for different mixes, a great value of porosity leads, as expected, to low values of mechanical prop- 
erties for instance. However, for a same mix, no correlation is found between these parameters (Larrard de et al., 2009).

Table 2. Expected value and standard deviation for the 9 variable input parameters of the model

\begin{tabular}{cccc}
\hline & & Expected value & Standard deviation \\
\hline$\phi$ & {$[-]$} & 0.129 & 0.010 \\
$\tau$ & {$[-]$} & 0.134 & 0.020 \\
$E$ & {$[\mathrm{GPa}]$} & 45.0 & 4.5 \\
$\nu_{0}$ & {$[-]$} & 0.178 & 0.044 \\
$\alpha$ & {$[-]$} & $5.25 \cdot 10^{-12}$ & $5.25 \cdot 10^{-13}$ \\
$k$ & {$[\mathrm{GPa}]$} & 137.7 & 13.8 \\
$\beta$ & {$[-]$} & 0.15 & 0.03 \\
$\varepsilon_{D}$ & {$[\mu \mathrm{m} / \mathrm{m}]$} & 109 & 16 \\
$A$ & {$[-]$} & 0.95 & 0.10 \\
\hline
\end{tabular}

The outputs of interests of these 1000 simulations are of course the lifespan of the structure (being the time when the damage variable reaches the critical value of 1 , which corresponds to the structure failure) and also the damage evolution in time.

\section{Results and discussion}

\subsection{Lifespan distribution}

The expected value for the lifespan of the concrete structure, evaluated on the 1000 realisations, is 979.82 years. The observed standard deviation is 393.05 years, which corresponds to a coefficient of variation of $40 \%$. Of course, this important value for the coefficient of variation must be compared to the variability of the 9 input parameters, whose coefficient of variability ranges between 10 and $25 \%$. Thus, the coupled problem we are dealing with leads to an increasing uncertainty.

It is interesting to note that lifespan follows a log-normal distribution, whereas all input parameters are distributed according to a Beta law. The parameters of the log-normal distribution are calculated directly from the observed expected value and standard deviation of the lifespan considered as a random variable. The parameters $\left(\mu_{T}, \sigma_{T}\right)$ of the log-normal law are expressed in Equations [22] and [23], where $E_{T}$ and $V_{T}$ are the expected value and the variance of the observed random variable.

$$
\mu_{T}=\ln \left(E_{T}\right)-\frac{1}{2} \ln \left(1+\frac{V_{T}}{E_{T}^{2}}\right)
$$




$$
\sigma_{T}=\ln \left(1+\frac{V_{T}}{E_{T}^{2}}\right)
$$

Figure 11 shows the lifetime distribution that has been calculated on the 1000 realisations, which can be compared to the log-normal distribution calculated with the $\left(\mu_{T}, \sigma_{T}\right)$ parameters identified from the observations. The values of the parameters of the log-normal law are: $\mu_{T}=6.81$ and $\sigma_{T}=0.39$.

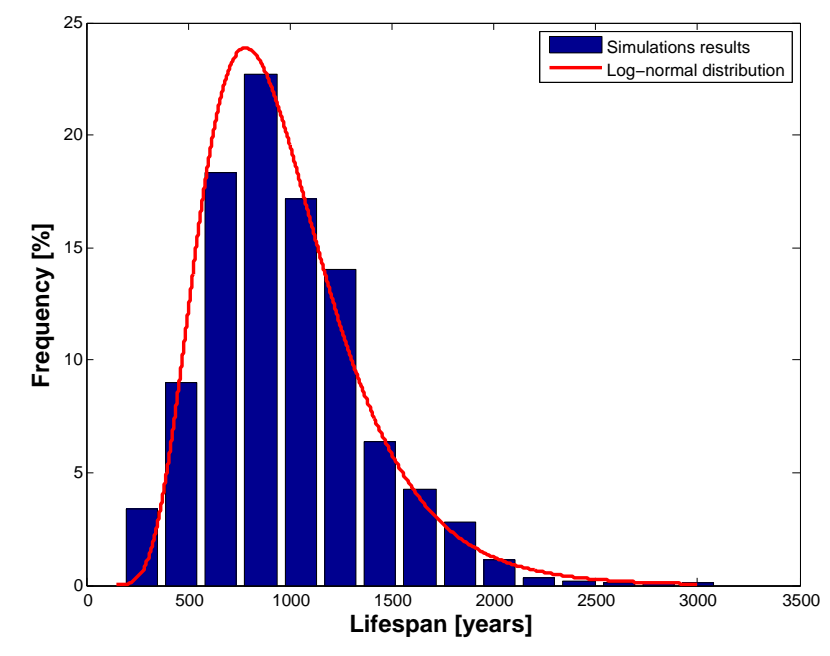

Figure 11. Lifespan distribution for the 1000 concrete structures simulated: accordance between the simulations results and a log-normal distribution

Knowing the lifespan distribution law allows to draw some quantitative conclusions linked with the following confidence intervals: $1 \%$ of the concrete columns are likely to be ruined before 370 years, $5 \%$ are likely to last less than 482 years, and $10 \%$ may not reach the age of 554 years.

The next section deals with sensitivity analysis and determines which parameters among all input variables are the most influent on the damage evolution with time and thus on the structure lifetime.

\subsection{Parametric survey}

To achieve this parametric survey, the Pearson's product-moment correlation coefficient is calculated for all the 9 input parameters, with regard to the total damage variable at every timestep. The Pearson's correlation coefficient cor is a well-known 
indicator of the linear correlation between two parameters, $x$ and $y$, and is obtained by dividing the covariance of these two variables by the product of their standard deviations [24]. Let us remind that the Pearson's correlation coefficient ranges from -1 to 1 , and that a value of 1 or -1 signifies a perfectly linear relationship between the two variables (if it is equal to $1, y$ increases when $x$ does as well, whereas a value of -1 means that $y$ decreases when $x$ increases). A value of 0 means that there is no linear relationship between the two variables. Unless correlation does not mean statistical dependance, it is a good indicator for models parameters sensitivity.

$$
c o r=\frac{\sum\left(x_{i}-\bar{x}\right)\left(y_{i}-\bar{y}\right)}{\sqrt{\sum\left(x_{i}-\bar{x}\right)^{2} \sum\left(y_{i}-\bar{y}\right)^{2}}}
$$

Figure 12 represents the Pearson's correlation coefficient evolution with time, for each of the 9 input parameters. The first comment on this figure is that there are two distinct periods. Indeed, before 175 years approximatively, all 1000 columns have an evolving damage variable, whereas from 175 years to the end of the studied period, some columns have already reached their ruin and have their damage variable constant to 1 . This means that for long periods many columns have a constant damage variable, which minimises the influence of the input variability. It is a sort of buffer effect which explains why the correlation coefficients get closer to 0 with time.

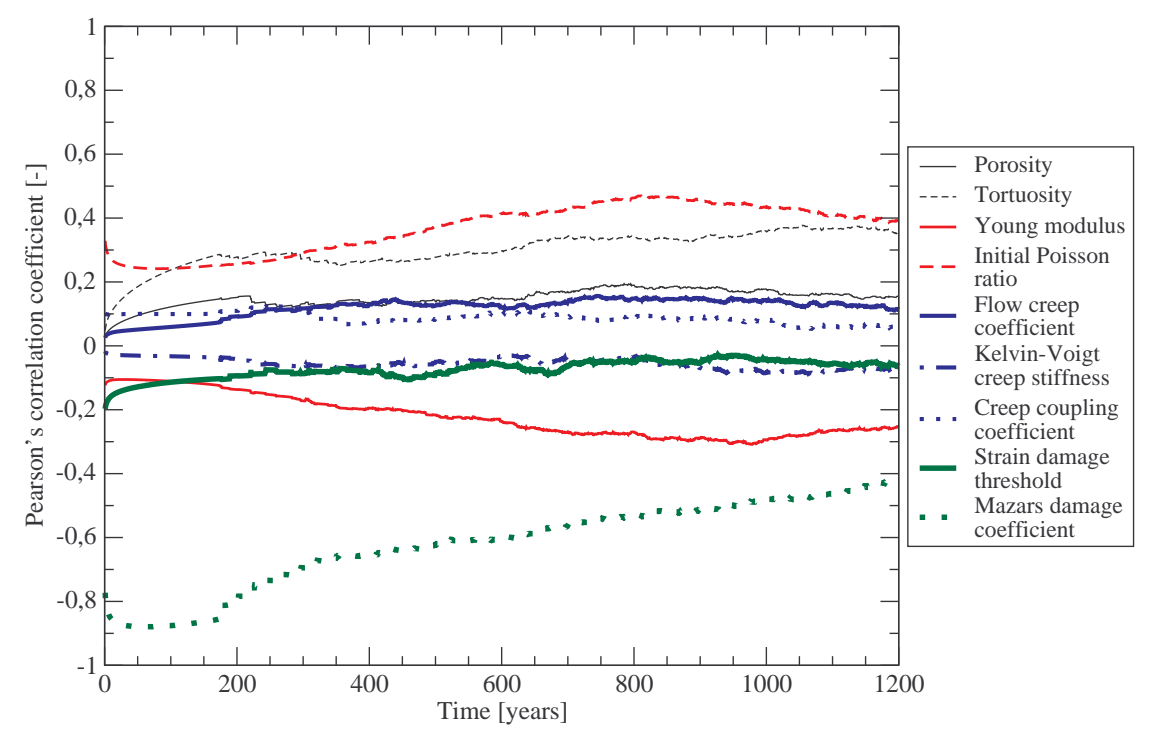

Figure 12. Evolution with time of the Pearson's correlation coefficient between the input parameters and the total damage variable 
The first conclusion is that the most influent parameter (in term of variability) is the Mazars damage coefficient $A$. Indeed, this coefficient is related to the mechanical behaviour of the material. Basically, the higher the coefficient $A$, the more important the compressive strength. Therefore, it is logical to find an important negative value for the Pearson's coefficient of parameter $A$.

The second most important parameter is the initial apparent Poisson ratio. Indeed, in our case, the structure is loaded in pure compression, but the material damages only through tensile strains. Now, it appears clearly in Equations [18] and [19] that the Poisson ratio is the link between the longitudinal compressive strain and the lateral tensile strains. The more important the Poisson ratio, the more important the tensile strains.

Almost as important as the Poisson ratio is the coefficient of tortuosity. Indeed, the higher the tortuosity, the faster the leaching degradation. It appears clearly on Figure 5 that the chemical damage represents an important part of the total damage before the ruin of the material, even though the ruin itself is due to the mechanical damage (tertiary creep). It can be assumed that the porosity does not appear as influent as the tortuosity (cf. Larrard de et al. (2010) for the relative influence of these parameters on the leaching process) mainly because the variability is more important for tortuosity than for porosity. This study shows the necessity of acquiring experimental data on the Poisson ratio variability.

Another important parameter is the Young modulus. Once again, it is due to the pure compressive loading of the structure whereas only tensile strains participate to the damage evolution: the more important the Young modulus, the fewer the longitudinal strains and therefore the lower the damage.

One can also mention the tensile strain damage threshold, which seems to be more influent in the first years than in the last ones. Physically, the role of the damage threshold is obvious: the bigger it is, the later the mechanical damage appears in the material. The decreasing influence of this parameter is precisely due to the fact that this parameter is very important during the first phase of damage evolution (its appearance and what corresponds to primary creep).

One can observe that the creep parameters variability has a very little influence on the lifespan variability, especially the Kelvin-Voigt stiffness $k$ and the coupling coefficient $\beta$. It is also worth noting that the first years are rather influenced by the chemical degradation parameters variability and the damage threshold, whereas the last years are under the influence of the Young modulus and the Poisson ratio. This can be explained by the fact that during the first years, when many columns do not have mechanical damage yet, the chemical degradation (faster in the first years than later, as it approximatively evolves with the square root of time) is the main contribution to the total damage. On the contrary during the last years, when tertiary creep appears, the mechanical parameters are the most influent on the damage evolution. 


\subsection{Lifetime classification}

The Pearson's correlation coefficient enhances the primary importance of the variability of the Mazars damage evolution coefficient $A$, the initial Poisson ratio $\nu_{0}$, the Young modulus $E$ and the tortuosity $\tau$ (standing for the chemical damage evolution). Nevertheless, it would be interesting to organise into a hierarchy these parameters and to establish threshold values for which a structure could be considered as secure or not (with regard to its lifespan).

This is achieved by constructing a decision tree from all the data collected through this calculation campaign (Breiman et al., 1984). The structures are classified depending on their lifespan: a first category is constituted with the columns whose lifespan is less than 370 years (1\% of the structures according to the lifespan distribution that has been identified), the second category is the columns with a lifespan between 370 and 482 years (between $1 \%$ and $5 \%$ of the shortest lifespans)...

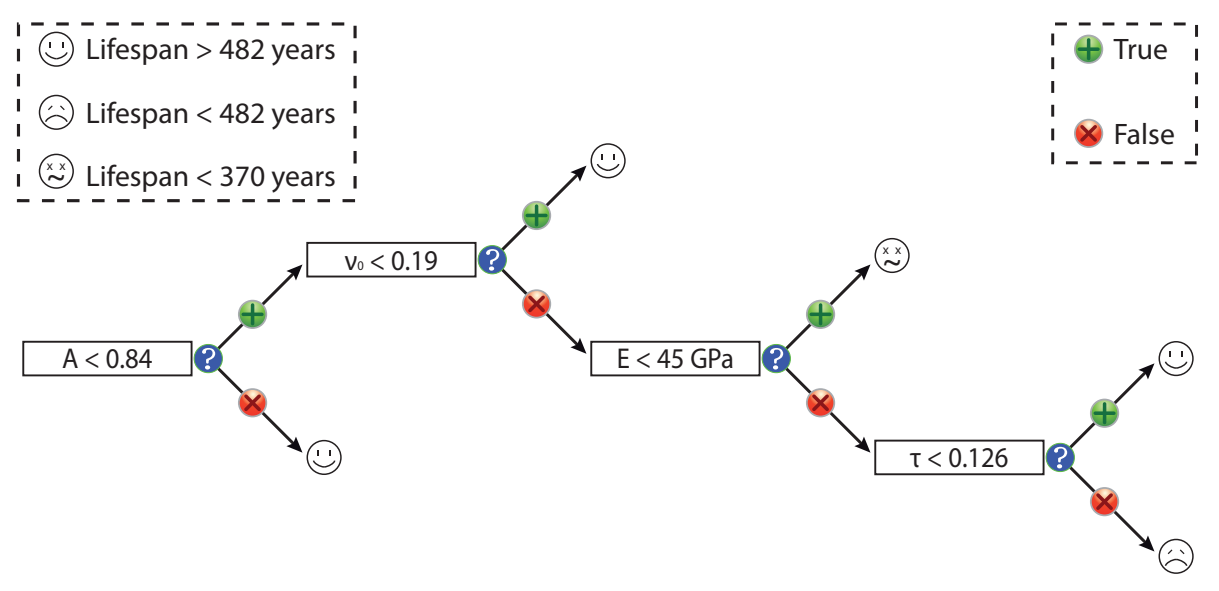

Figure 13. Schematic representation of the classification tree: each case represents a condition on a parameter, the up-going branch means that the condition is satisfied, whereas the down-going branch means that it is not. The smiling face stands for a column with a lifespan over 482 years. The sad face stands for a lifespan between 370 and 482 years. The sick face corresponds to a critical lifespan (under 370 years). Are represented by order of importance: the damage evolution coefficient A (standing for the compressive strength), the Poisson ratio, the Young modulus and the tortuosity

The complete decision tree obtained with the whole data is too complicated and large to present any real use. However, a few levels of pruning and focusing the attention on the two first mentionned categories lead to the following classification tree, which is in good accordance with the conclusions drawn from the Pearson's coefficient study:

1) if $A \geq 0.84$, then the column is secure (lifespan greater than 482 years); 
2) if $A<0.84$ but $\nu_{0}<0.19$, then the column is secure;

3) if $A<0.84$ and $\nu_{0} \geq 0.19$ and $E<45 \mathrm{GPa}$, then the column is among the $1 \%$ columns with the shortest lifespan ;

4) if $A<0.84$ and $\nu_{0} \geq 0.19$ and $E \geq 45 \mathrm{GPa}$ but $\tau<0.126$, then the column is secure;

5) if $A<0.84$ and $\nu_{0} \geq 0.19$ and $E \geq 45 \mathrm{GPa}$ but $\tau \geq 0.126$, then the column is among the 5\% columns with the shortest lifespan.

This decision tree is illustrated on Figure 13.

\section{Conclusions}

A model for calcium leaching was developed on the one hand, based on the calcium mass balance Equation. On the other hand, creep strain evolution was modelled with the microprestress solidification theory. Both models have been coupled in a totally implicit numerical scheme aiming at evaluating the damage evolution with time of a concrete column under pure compression and exposed to leaching and creep at the same time. The mechanical damage evolution is the one proposed by Mazars (1984) introducing creep strain through a coupling coefficient.

The aim of this study was to investigate the influence of the input parameters variability of the coupled model on the lifespan of the considered structure. Let us remind here that very strong assumptions have been considered for this study (uniaxial stress state, unidirectional degradation front in leaching, coupling with creep only, etc.) and therefore, these conclusions cannot be extended to more complex structures. It was shown that even though a Beta distribution was proposed for all input parameters, lifespan is distributed according to a log-normal law, whose coefficients have been identified, which allows to determine fractiles (with regard to pathologic lifespans).

It has also been shown that the input parameters whose variability had the most important influence on the lifespan distribution are the coefficient ruling the damage evolution (which is related to the compressive strength), the Poisson ratio, the Young modulus and the coefficient of tortuosity (accounting for the chemical degradation due to leaching). On the contrary, creep parameters variability has a minor role. At last, a decision tree allowed to determine threshold values for these influent parameters so as to determine whether the lifespan of the considered structure could present any particular risk with regard to the structure durability.

\section{Acknowledgements}

The investigations and results reported herein are supported by the National Research Agency (France) under the APPLET research program (grant ANR-06-RGCU001-01). 


\section{References}

ACI Committee 209, Guide for Modeling and Calculating Shrinkage and Creep in Hardened Concrete, Technical Report n 209.2R-08, American Concrete Institute, 2008.

Adenot F., Durabilité du béton : caractérisation et modélisation des processus physiques et chimiques de dégradation du ciment, PhD thesis, Université d'Orléans, 1992.

Bajza A., Rousekeva I., Vrana O., "Corrosion of hardened cement paste by ammonium nitrate”, 8th International Congress of the chemistry of cement, vol. V, p. 99-103, 1986.

Bangert F., Kuhl D., Meschke G., " Finite element simulation of chemo-mechanical damage under cyclic loading conditions”, in R. de Borst, J. Mazars, G. Pijaudier-Cabot, J. van Mier (eds), Fracture Mechanics of Concrete Structures, vol. 1, p. 145-152, 2001.

Bazant Z. P., Hauggaaed A. B., Baweja S., Ulm F. J., “ Microprestress-solidification theory for concrete creep. I: Aging and drying effects", Journal of Engineering Mechanics, vol. 123, $\mathrm{n}^{\circ}$ 11, p. 1188-1194, 1997a.

Bazant Z. P., Prasannan S., " Solidification theory for concrete creep. I. Formulation”, Journal of Engineering Mechanics, vol. 115, n 8, p. 1691-1703, 1989.

Bazant Z. P., Xiang Y., " Crack growth and life time of concrete under long time loading”, Journal of Engineering Mechanics, vol. 123, n 4, p. 350-358, $1997 \mathrm{~b}$.

Benboudjema F., Modélisation des déformations différées du béton sous sollicitations biaxiales. Application aux bâtiments réacteurs de centrales nucléaires, $\mathrm{PhD}$ thesis, Université de Marne-La-Vallée, 2002.

Benboudjema F., Meftah F., Torrenti J. M., “'Interaction between drying, shrinkage, creep and cracking phenomena in concrete", Engineering Structures, vol. 27, p. 239-250, 2005a.

Benboudjema F., Meftah F., Torrenti J. M., “ Structural effects of drying shrinkage”, Journal of Engineering Mechanics, vol. 131, n 11, p. 1195-1199, 2005 b.

Benboudjema F., Torrenti J. M., “ Early age behaviour of concrete nuclear containments”, Nuclear Engeneering and Design, vol. 238, n 10, p. 2495-2506, October, 2008.

Bentz D. P., Garboczi E. J., " Modeling the leaching of calcium hydroxide from cement paste: effect on pore space percolation and diffusivity”, Materials and Structures, vol. 25, p. 7379, 1995.

Berner U., " Modelling the incogruent dissolution of hydrated cement minerals", Radiochim. Acta, vol. 44/45, p. 387-393, 1988.

Berner U., " A thermodynamic description of the evolution of the pore water chemistry and uranium speciation during the degradation of cement", NAGRA TR 90-12 \& PSI Ber. $n^{\circ} 62$, 1990.

Berthollet A., Georgin J. F., Granger L., Reynouard J. M., “ Modeling of the non-linear creep and cracking combined effects on concrete structures", in Elsevier (ed.), Creep, shrinkage and durability mechanics of concrete and other quasi-brittle materials, Pro. intern. symp, Boston, August 20-22, 2002.

Berveiller M., Le Pape Y., Sudret B., Perrin F., “ Bayesian updating of the long-term creep deformations in concrete containment vessels using a non intrusive method", 10th International Conference on Applications of Staistics and Probability in Civil Engineering, Tokyo, Japan, 2007. 
Bourdette B., Durabilité du mortier : prise en compte des auréoles de transition dans la caractérisation et modélisation des processus physiques et chimiques d'altération, $\mathrm{PhD}$ thesis, INSA Toulouse, 1994.

Breiman L., Friedman J. H., Olshen R. A., Stone C. J., Classification and regression trees, Wadsworth, Belmont, 1984.

Brooks J. J., " 30-year creep and shrinkage of concrete”, Magazine of concrete research, vol. 57, n 9, p. 545-556, November, 2005.

Buil M., Ollivier J. P., La durabilité des bétons, Presse de l'Ecole Nationale des Ponts et Chaussées, chapter "Conception des bétons : la structure poreuse", p. 57-106, 1992a.

Buil M., Revertégat E., Oliver J., A Model of the Attack of Pure Water or Undersaturated Lime Solutions on Cement, vol. 2nd, American Society for Testing and Materials, Philadelphia, p. 227-241, 1992b.

Carde C., Francois R., " Effect of the leaching of calcium hydroxyde and C-S-H from cement paste on mechanical and physical properties", Cement and Concrete Research, vol. 27, p. 539-550, 1997.

Carde C., Francois R., Torrenti J. M., “ Leaching of both calcium hydroxyde and CSH from cement paste. Modeling the mechanical behavior.", Cement and Concrete Research, vol. 26, n० 8, p. 1257-1268, 1996.

Celia M., Bouloutas E., Zarba R., “ A general mass conservative numerical solution for the unsaturated flow equation”, Water Res. Res., vol. 26, n 7, p. 1483-1496, 1990.

Chen J. J., Thomas J. J., Taylor H. F. W., Jennings H. M., " Solubility and structure of calcium silicate hydrate", Cement and Concrete Research, vol. 34, p. 1499-1520, 2004.

Eymard R., Gallouet T., Hilhorst D., Slimane Y. N., " Finite volumes and non linear diffusion equations", Mathematical Modelling and Numerical Analysis, vol. 32, n 6, p. 747-761, 1998.

Gérard B., Contribution des couplages mécaniques-chimie-transfert dans la tenue à long terme des ouvrages de stockage de déchets radioactifs, PhD thesis, ENS Cachan, 1996.

Gérard B., Le Bellégo C., Bernard O., " Simplified modelling of calcium leaching of concrete in various environment", Materials and Structures, vol. 35, p. 632-640, 2002.

Gérard B., Pijaudier-Cabot G., Laborderie C., " Coupled diffusion-damage modelling and the implications on failure due to strain localization”, Int. J. Solids Struct., vol. 35, n ${ }^{\circ} 31-32$, p. 4107-4120, 1998.

Guillon E., Durabilité des matériaux cimentaires : modélisation de l'influence des équilibres physico-chimiques sur la microstructure et les propriétés mécaniques résiduelles., $\mathrm{PhD}$ thesis, ENS Cachan, 2004.

Harris A. W., Manning M. C., Tearle W. M., Tweed C. J., " Testing models of the dissolution of cements-leaching of synthetic CSH gels", Cement and Concrete Research, vol. 32, p. $267-$ $271,2002$.

Heukamp F. H., Ulm F. J., Germaine J. T., “ Mechanical properties of calcium-leached cement pastes: triaxial stress states and the influence of the pore pressures", Cement and Concrete Research, vol. 31, n 5, p. 767-774, 2001.

Illston J. M., " The components of strains in concrete under sustained compressive stress", Magazine of concrete research, vol. 17, n 50, p. 21-28, 1965. 
Jason L., Huerta A., Pijaudier-Cabot G., Ghavamian S., “ An elastic plastic damage formulation for concrete: application to elementary tests and comparison with isotropic damage model", Computer Methods in Applied Mechanics and Engineering, vol. 195, $\mathrm{n}^{\circ}$ 52, p. 7077-7092, 2006.

Jennings H. M., Xi Y., Relationships between microstructure and creep and shrinkage of cement paste, Material Science of Concrete, The American Ceramic Society, Westerville, OH, p. 37-69, 1992.

Kamali-Bernard S., Bernard F., Prince W., " Computer modelling of tritiated water diffusion test for cement based materials", Computational Materials Science, vol. 45, n 2, p. 528-535, April, 2009.

Kirkpatric S., Gelatt C. D., Vecchi M. P., “ Optimization by Simulated Annealing”, Science, vol. 220, n 4598, p. 671-680, 1983.

Kuhl D., Bangert F., Meschke G., " Coupled chemo-mechanical deterioration of cementitious materials - Part 1: modeling”, International Journal of Solids and Structures, vol. 41, p. 15 40, 2003a.

Kuhl D., Bangert F., Meschke G., “ Coupled chemo-mechanical deterioration of cementitious materials - Part 2: numerical method and simulation”, International Journal of Solids and Structures, vol. 41, p. 41-67, 2003b.

Kupfer H. B., Hilsdorf H. K., Rusch H., “ Behavior of concrete under biaxial stresses”, ACI Journal, vol. 66, p. 656-666, 1969.

Lacarrière L., Sellier A., Bourbon X., “ Concrete mechanical behaviour and calcium leaching weak coupling”, Revue Européenne de Génie Civil, vol. 10, n 9, p. 1147-1175, 2006.

Larrard de T., Benboudjema F., Colliat J. B., Torrenti J. M., Deleruyelle F., “ Correlations between measures and development of a predictive model for the long-term behavior of concrete structures subjected to leaching”, NUCPERF 2009 EFC Event 317, RILEM, 2009.

Larrard de T., Benboudjema F., Colliat J. B., Torrenti J. M., Deleruyelle F., “ Concrete calcium leaching at variable temperature: experimental data and numerical model inverse identification", Submitted to Computational Materials Science, 2010.

Li Z., “Effective creep Poisson's ratio for damages concrete”, International Journal of Fracture, vol. 66, p. 189-196, 1994.

Mainguy M., Tognazzi C., Torrenti J. M., Adenot F., “ Modelling of leaching in pure cement paste and mortar.", Cement and Concrete Research, vol. 30, p. 83-90, 2000.

Mazars J., Application de la mécanique de l'endommagement au comportement non linéaire et à la rupturedu béton de structure, PhD thesis, ENS Cachan, 1984.

Mazars J., “ A description of micro and macroscale damage of concrete”, Engineering Fracture Mechanics, vol. 25, p. 729-737, 1986.

Mazzotti C., Savoia M., “ Nonlinear creep damage model for concrete under axial compression”, Journal of Engineering Mechanics, vol. 129, n 9, p. 1065-1075, 2003.

McKay M. D., Conover W. J., Beckman R. J., “ A comparison of three methods for selecting values of input variables in the analysis of output from a computer code", Technometrics, vol. 21, p. 239-245, 1979.

Moranville M., Kamali S., Guillon E., “ Physicochemical equilibria of cement-based materials in aggressive environments - experiment and modeling", Cement and Concrete Research, vol. 34, n 9, p. 1569-1578, September, 2004. 
Moskowicz P., Poussin J., Sanchez F., “ Diffusion and dissolution in a reactive porous medium : Mathematical modelling and numerical simulations", Journal of Computanional and Applied Mathematics, vol. 66, p. 377-389, 1996.

Nguyen V. H., Colina H., Torrenti J. M., Boulay C., Nedjar B., “ Chemomechanical coupling behaviour of leached concrete. Part 1: experimental results", Nuclear Engeneering and Design, vol. 237, p. 2083-2089, 2007a.

Nguyen V. H., Nedjar B., Colina H., Torrenti J. M., “ A separation of scales homogenisation analysis for the modelling of calcium leaching in concrete", Computer Methods in Applied Mechanics and Engineering, ${ }^{\circ}$ 195, p. 7196-7210, 2006.

Nguyen V. H., Nedjar B., Torrenti J. M., “ Chemomechanical coupling behaviour of leached concrete. Part 2: modelling”, Nuclear Engeneering and Design, vol. 237, p. 2090-2097, 2007b.

Ollivier J., Maso J. C., Bourdette B., “Interfacial transition zone in concrete”, Advanced Cement Based Materials, vol. 2, p. 30-38, 1995.

Omar M., Pijaudier-Cabot G., Loukili A., “Numerical models for coupling creep and fracture of concrete structures", in Balkema (ed.), Computationel Modelling of concrete structures Euro-C, Proc. intern. symp., St Johan, March, 2003.

Ozbolt J., Reinhardt H. W., Creep, shrinkage and durability mechanics of concrete and other quasi-brittle materials, F. J. Ulm, Z. P. Bazant and F. H. Witmann, Elsevier, Cambridge, chapter Creep-cracking interaction of concrete - three dimensional finite element model, p. 221-228, 2001.

Poyet S., Torrenti J. M., “ Caractérisation de la variabilité des performances des bétons. Application à la durabilité des structures (groupe de travail APPLET)", Annales du BTP (in press), 2009.

Revertégat E., Richet E., Gegout P., “Effect of pH on the durability of cement pastes”, Cement and Concrete Research, vol. 22, p. 259-272, 1992.

Reviron N., Etude du fluage des bétons en traction. Application aux enceintes de confinement des centrales nucléaires à eau sous pression, $\mathrm{PhD}$ thesis, ENS Cachan, 2009.

Reviron N., Benboudjema F., Torrenti J. M., Nahas G., Millard A., " Coupling between creep and cracking in tension", 6th International Conference on Fracture Mechanics of Concrete and Concrete Structures, Italie, June, 2007.

Richet C., Le Callonec C., Mazoin C., Pin M., Adenot F., Amélioration du modèle de dégradation de la fiabilité du modèle DIFFUZON., Technical Report n RT SESD/97.60, CEA, 1997.

Roll R., “Long time creep-recovery of highly stressed concrete cylinders”, ACI SP-9, Symp. on Creep, Portland Cement Association, Detroit, p. 115-128, 1964.

Saetta A., Scotta R., Vitaliani R., “ Mechanical behavior of concrete under physical-chemical attacks”, Journal of Engineering Mechanics (ASCE), vol. 124, p. 1100-1109, 1998.

Schrefler B., " Mechanics and thermodynamics of saturated-unsaturated porous materials and quantitative solutions.", Applied Mechancs Review ASME 55, vol. 4, p. 351-388, 2002.

Thomas J. J., Jennings H. M., Allen A. J., “ The surface area of cement paste as measured by neutron scattering : evidence for two C-S-H morphologies", Cement and Concrete Research, vol. 28, n 6, p. 897-905, 1998. 
Tognazzi C., Couplage fissuration-dégradation chimique dans des matériaux cimentaires : caractérisation et modélisation, PhD thesis, INSA Toulouse, 1998.

Torrenti J. M., Didry O., Ollivier J., Plas F., La dégradation des bétons - couplage fissurationdégradation chimique, Hermès, 1999.

Torrenti J. M., Nguyen V. H., Colina H., Le Maou F., Benboudjema F., Deleruyelle F., “ Coupling between leaching and creep of concrete", Cement and Concrete Research, vol. 38, $\mathrm{n}^{\circ}$ 6, p. 816-821, June, 2008.

Ulm F. J., Torrenti J. M., Adenot F., “ Chemoporoplasticity of calcium leaching in concrete”, Journal of Engineering Mechanics, vol. 125, n 10, p. 1200-1211, 1999. 